\title{
A pulsão como unidade, multiplicidade e dualidade na teoria pulsional freudiana
}

\author{
Drive as unity, multiplicity and duality in the Freudian drive theory
}

\author{
RICARDO RODRIGO FRANÇA DA SILVA \\ MIRIAN IZOLINA PADOIN DALLA ROSA
}

\begin{abstract}
Resumo: A presente pesquisa estuda um dos conceitos principais da psicanálise, a saber, a pulsão. Esse conceito sofreu diversas modificações ao longo de sua elaboração, durante a pesquisa clínica de Freud, o pai da psicanálise, não tendo sido totalmente deslindado por ele. Desde a sua morte, afloraram diversas conjecturas acerca de sua concepção de pulsão, que, não raramente, implicam em erros teóricos e, conseguintemente, metodológicos. Freud também não estava seguro sobre esse conceito ao formulá-lo, visto que, inicialmente, havia apenas algo análogo a pulsão de vida, associada, no Projeto, ao princípio de constância. Por vezes, considerou que a pulsão de morte seria a primeira pulsão ou pulsão por excelência. Tais imprecisões dificultaram a compreensão desse conceito e continuam a confundir os estudiosos que iniciam na psicanálise. Desse modo, a pesquisa tem como objetivo geral explicitar os modos limitados de representar a pulsão, a saber, como unidade, dualidade, multiplicidade, o que implica, portanto, nos seguintes objetivos: a) Explicitar como efetivou-se a concepção do conceito de Pulsão; b) descrever o desenvolvimento da concepção acerca da pulsão como multiplicidade - pulsões parciais - à pulsão de vida; c) destacar os limites da linguagem descritiva como meio de representar a pulsão -pulsão de morte. Para tanto, utilizar-se-á como método a revisão bibliográfica. Considera-se que a pulsão é uma unidade, por um lado, ao mesmo tempo em que é dualidade e multiplicidade, mas, também, por ser semovente, não pode ser - tal como a morte - totalmente representada, tanto no plural quanto no modo singular.
\end{abstract}

Palavras-Chave: Pulsão. Pulsão de vida. Pulsão de morte.

Abstract: This research studies one of the main concepts of psychoanalysis, namely, the Drive. This concept underwent several modifications during its elaboration, during the clinical research of Freud, the father of psychoanalysis, and was not completely developed by him. Since his death, several conjectures have surfaced about his conception of drive, which, not infrequently, implies theoretical and, consequently, methodological errors. Freud was also not sure about this concept when formulating it, since, initially, he thought only something analogous to life drive, associated, in the Project, with the principle of constancy. At times, he considered that the death drive would be the first drive or drive par excellence. Such inaccuracies made it difficult to understand this concept and continue to confuse scholars who begin with psychoanalysis. In this way, the research has as general objective to explain the limited ways of representing the drive, namely, as unity, duality, multiplicity, which implies, therefore, in the following objectives: a) To explain how the conception of Drive took place; b) describe the development of the conception about the drive as multiplicity - partial drives - to the life drive; c) highlight the limits of descriptive language as a means of representing the drive - death drive. To this end, the bibliographic review will be used as a method. The drive is considered to be a unit, on the one hand, at the same time that it is duality and multiplicity, but also, because it is moving, it cannot be like death - fully represented, both in the plural and in the way singular.

\footnotetext{
${ }^{1}$ PUCPR - Campus Toledo. E-mail: rodrigo.ricardo.franca@hotmail.com

${ }^{2}$ Orientadora deste trabalho, professora do curso de psicologia da PUCPR - Campus Toledo. E-mail: miriam.rosa@pucpr.br
} 
Keywords: Pulsation. Life drive. Death drive.

\section{Introdução}

A presente pesquisa estuda um dos conceitos principais da psicanálise, a saber, a pulsão. Esse conceito sofreu diversas modificações ao longo de sua elaboração, durante a pesquisa clínica de Freud, não tendo sido totalmente deslindado por ele. Desde a sua morte, afloraram diversas conjecturas acerca de sua concepção de pulsão, que, não raramente, implicam em equívocos teóricos e, conseguintemente, metodológicos. Freud também não estava seguro sobre esse conceito ao formulá-lo, visto que, inicialmente, havia apenas algo análogo a pulsão de vida, associada, no Projeto, ao princípio de constância. Posteriormente, pautado na experiência clínica e no problema da repetição, tece conjecturas sobre a pulsão de morte.

Freud propiciou o entendimento de que existiria uma dualidade pulsional desde o início, embora, tenha ressaltado as limitações linguísticas e do vocabulário filosófico. Por vezes, considerou que a pulsão de morte seria a primeira pulsão ou pulsão por excelência. Tais imprecisões dificultaram a compreensão desse conceito e continuam a confundir os estudiosos que iniciam na psicanálise. Assim, a pesquisa teve como objetivo geral explicitar os modos descritivos e limitados de representar a pulsão, a saber, como unidade, dualidade, multiplicidade.

A primeira parte do presente estudo teve como ponto de partida a clássica definição de pulsão, presente em Pulsões e Destinos da Pulsão (1915), em que são retomadas as origens da concepção pulsional, evidentes no Projeto para uma psicologia científica (1895), a fim de explicitar as características da pulsão como um estímulo interno de quantidades de energia não vinculadas. Nessa ocasião, verificase que a pulsão, enquanto quantidade de energia, refere-se, dentro dos limites da linguagem, a uma unidade, muito embora a palavra "unidade" abarque apenas parcialmente a pulsão, não podendo representá-la, visto que ela é semovente.

A segunda parte considerou a pulsão como multiplicidade e como dualidade. Em Três Ensaios sobre a teoria da sexualidade (1905), Freud considera a multiplicidade de pulsões que resultam no que mais tarde denomina como pulsão de vida. Recorre-se, ainda, ao Á Guisa de Introdução ao Narcisismo (1914), no qual Freud aglutina as Pulsões de autoconservação e Pulsão Sexual. Assim, as pulsões parciais estão contidas dentro do conjunto denominado pulsão de sexual - Eros -, que, juntamente com a pulsão de autoconservação, compõem o que Freud denomina como pulsão de vida.

A pulsão de morte foi considerada, na parte terceira, na qual se recorre, principalmente, ao Além do princípio de Prazer, Análise terminável e Interminável e a Por que Guerra? Busca-se ressaltar o aspecto irrepresentável da pulsão de morte, 
bem como a dificuldade de Freud ao conjecturar sobre a pulsão de morte, visto que a linguagem utilizada por Freud, as metáforas biológicas, filosóficas, mitológicas, não permitem abarcar a pulsão, exceto descritivamente: como unidade, dualidade, multiplicidade.

Inicialmente, contudo, as características da Pulsão foram descritas no Projeto de 1895 , visto que o jovem neurologista postulava que o organismo funcionava de acordo com o princípio de constância (FREUD, 1996a, p. 357). Para dar conta da homeostase, haviam dois grupos de neurônios, os impermeáveis (PSY), e os permeáveis (PHI), correlativos ao processo primário e o processo secundário. Os permeáveis eram responsáveis por manter o organismo livre dos estímulos externos que pudessem abalar o equilíbrio homeostático, já os impermeáveis eram responsáveis por lidar com a energia interna produzida pelas células, o estímulo interno e constante que mais tarde foi nomeado como pulsão (FREUD, 1996a).

A energia intracelular acumulava-se nos terminais neuronais e forçavam a passagem pela via axional, o que Freud denomina como soma. Quando a energia elevava-se acima do limiar fechneriano, surgiam, após inúmeras facilitações, o afeto e a idéia, o que também pode ser denominado como energia em estado ligado, isto é, com representações como objeto, e, por outro lado, quando abaixo do limiar, o que não é nem afeto e nem representação, tal como a morte, a pulsão de morte. Quando não representada, isto é, quando a energia não encontrava uma representação pela qual se deslocar e condensar, acabava circulando livremente por todo o psiquismo, efetivando-se por vias tortuosas, via repetição oriunda tanto do principio de prazer, quanto de além do principio de prazer (FREUD, 1996a, p. 353 361). Assim, é possível verificar que já no projeto Freud apontava o estimulo interno como algo anterior ao recalque primário, de além das pulsões parciais, e de além do principio de prazer, o que poderia caracterizar a pulsão como uma unidade a priori, a Coisa, como pontua no Projeto; e os predicados da coisa - os destinos da pulsão viriam depois (FREUD, 1996a, p. 414).

Contudo, em A Interpretação dos Sonhos, Freud deixa de lado o projeto, o aspecto somático, e passa a considerar apenas o aspecto psicológico. Ele despreza "[...] por completo o fato de que o aparelho anímico em que estamos aqui interessados é-nos também conhecido sob a forma de uma preparação anatômica" (FREUD, 1996b, p. 541-595), decidindo não mais se preocupar com o aspecto anatômico e somático do psiquismo: "[...] evitarei cuidadosamente a tentação de determinas essa localização como se fosse anatômica. Permanecerei no campo psicológico" (FREUD, 1996b, p. 541-595). Ressalta que a linguagem neurológica é limitada, além de perceber que a psiquiatria pouco pode contribuir para a saúde das histéricas. Avança seus estudos e passa a considerar as pulsões que surgem depois das primeiras inscrições, a saber, as pulsões de vida.

Apoiadas nas três zonas erógenas principais, e nas facilitações proporcionadas 
por quem executa a ação específica, tais zonas erógenas começam a se confluir, até que o bebê possa ter uma imagem de unidade de seu corpo (FREUD, 1996, p. 177178). Os diferentes impulsos se fundem, se combinam, entram em oposição, e se repetem de acordo com as experiências de satisfação, isto é de prazer/desprazer. $\mathrm{O}$ conjunto de todas as pulsões parciais passa a ser denominada como pulsão de vida. Assim, é possível compreender que as pulsões são múltiplas enquanto predicados da Coisa, isto é, quando a energia inicial, antes em estado livre, passa, agora, a ser vetorizada via diálogo tônico libidinal, ou seja, em estado ligado. Logo, fala-se em multiplicidades das pulsões quando se deve considerar o que vem depois do recalque primário, ou seja, pulsões parciais.

Entretanto, Freud percebe que, além das repetições referentes ao principio de prazer, rejeitado pelas contracatexias do ego e do superego, há algo que se repete independente do principio de prazer, isto é, independente de tudo o que é vetorizado após o recalque primário. Essas “[...] tendências que estariam além do princípio de prazer, isto é, tendências que seriam mais arcaicas e que atuariam de forma independente do princípio de prazer". (FREUD, 2006, p. 143), são correlatas a pulsão de morte. $O$ autor considera que a pulsão de vida, ou seja, o princípio de prazer "parece, de fato, estar a serviço das pulsões de morte". (FREUD, 2006, p. 181). Em alguns momentos retoma sua concepção energética, apoiada da biologia de August Weismann, para afirmar que "[...] a substância viva, ao ser vivificada, foi rompida em pequenas partículas que desde então anseiam por reunir-se novamente através das pulsões sexuais" (FREUD, 2006, p. 178), o que, por analogia, evidencia que a pulsão, inicialmente, é uma só, tornando-se, depois, múltipla, o que pode ser verificado no seguinte fragmento: "Essas partículas dispersas de substância viva atingiram assim o estado multicelular para afinal transferir para as células germinativas a pulsão para a reunificação, que estas últimas contêm de forma altamente concentrada" (FREUD, 2006, p. 178). (grifo nosso). Assim, as pulsões sairiam de um estado de unidade inorgânica e de completude - princípio de nirvana -, estilhaçando-se em uma multiplicidade pulsional, que busca, com base na satisfação, um retorno ao inorgânico - pulsão de morte.

Contudo, as incertezas continuam, visto que, sobre sua hipótese, Freud afirma que "[...] nem estou convencido, nem peço aos outros que acreditem nelas [...] não sei até que ponto acredito nelas” (FREUD, 2006, p. 178). Sua concepção não pretende exagerar-se em conjecturas teóricas, pois: "Quanto mais frequentemente isso é feito no decurso da construção de uma teoria, menos fidedigno, como sabemos, deve ser o resultado final" (FREUD, 1996e, p. 68). Trata-se, dessa forma, de um recurso mitológico e poético para explicar a sua concepção; no fundo, tudo é fantasia arquitetada pela configuração de impulsos de cada um, como afirma: “[...] cada um de nós seja dominado por preferências internas profundamente arraigadas 
que imperceptivelmente dirigem e inspiram nossa especulação". O que, de acordo com Freud, deve ser considerado com benevolência e humildade (FREUD, 2006, p. 178). A teoria Freudiana, portanto, não se oferece como uma única verdade, não se impõe como verdade única, apresenta-se como uma interpretação, dentre outras, que tem sua vantagem por compreender seus limites, o que fica evidente quando Freud recorre ao mito do andrógeno, o amor e discórdia de Empédocles, e pontua, em uma carta a Einstein que,no fundo, não podemos abarcar a Coisa com nossa linguagem científica, e que, mesmo a ciência, é uma convenção e em determinado momento acaba recorrendo ao mito, nas palavras de Freud a Einstein: "Talvez ao senhor possa parecer serem nossas teorias uma espécie de mitologia [...] Todas as ciências, porém, não chegam, afinal, a uma espécie de mitologia como esta? Não se pode dizer o mesmo, atualmente, a respeito de sua física?" (FREUD, 1996i, p. 216).

Em Análise Terminável e Interminável (1937), a característica mitológica também é ressaltada. Freud recorre à mitologia poética grega para nominar as transformações pulsionais. No referido texto, a pulsão de morte aparece como algo distribuído por todas as instâncias psíquicas e não pertence exclusivamente a só uma delas, indicando, inclusive, que é anterior ao Id. Destaca, ainda, que a pulsão de vida e de morte pode se misturar, difundir e se distribuir às outras instâncias:

Estamos lidando aqui com as coisas supremas que a pesquisa psicológica pode aprender: o comportamento dos dois instintos primevos, sua distribuição, mistura e difusão -coisas que não podemos imaginar como confinadas a uma única província do aparelho psíquico, ao id, ao ego ou ao superego. (FREUD, 1996b, p. 259).

No referido texto, destaca o caminho silencioso da pulsão de morte, ao percorrer as três instâncias, além de apontar algumas formas do surgimento dela na clínica, tais como a mescla com o superego, o apego ao sofrimento, o masoquismo, entre outras. Assim, por trás das instâncias, existiria um "instinto [pulsão] de morte original da matéria viva" (FREUD, 1996b, p. 256), os resíduos que não podem ser julgados, sobre os quais não é possível emitir um juízo, dos quais fala Freud, circulam livremente por todas as instâncias "O que chamamos de coisas são resíduos que fogem de serem julgados” (FREUD, 1996a, p. 396). A multiplicidade dos fenômenos da vida - os destinos da pulsão - seriam resultantes da primeira pulsão, os predicados da coisa. Todavia, pondera sobre a limitação de suas conjecturas, mais uma vez: "No momento, temos que nos curvar à superioridade das forças contra as quais vemos nossos esforços redundar em nada. Mesmo exercer uma influência psíquica sobre o simples masoquismo constitui um ônus muito severo para nossos poderes" (FREUD, 1996b, p. 257). Logo, fica ressaltado os limites da linguagem como meio de descrever a pulsão.

\section{Considerações finais}


Se fosse possível resumir em uma frase a conclusão que o presente estudo obteve, no que diz respeito à unidade, dualidade e multiplicidade das pulsões, ela seria resumida na frase de Nietzsche. "Também aqui tão como frequentemente, a unidade da palavra nada garante a unidade da coisa”. Logo, uma das conclusões decorrentes do presente estudo é a de que, ao falarmos em unidade, uma multiplicidade e uma dualidade das pulsões, são formas descritivas de falar de algo que, em si mesmo, não pode ser capturado por uma palavra. A palavra é uma forma de cristalizar a coisa; a palavra mata a coisa. As palavras permitem que tentemos nominar aquilo que não tem nome, e nunca terá, tanto do ponto de vista teórico quanto no ponto de vista de quem se submete à análise. Ao considerarmos a pulsão como unidade, como multiplicidade, ou como dualidade não a apreendemos completamente, devido ao seu aspecto semovente. A pulsão continua se movendo, independentemente das palavras que usamos para tentar nominá-la, apesar de tentarmos descrevê-la.

Logo, só importa saber sobre a pulsão na prática clínica, que emerge como algo não simbolizado e se repete enquanto a palavra do paciente não pode escoar o excesso de pulsão, enquanto a palavra não matar a coisa. Sobre isso, verifica-se, ainda, que há duas repetições: uma repetição de algo referente ao princípio de prazer, das pulsões de vida, e uma repetição de quantidades de pulsão anteriores ao princípio de prazer (de algo além do princípio de prazer/pulsão de vida). Todavia, esses modos descritivos, ainda assim, são uma simplificação. Freud mesmo acrescenta que os Três Ensaios está longe de apresentar um estudo exaustivo sobre a teoria das pulsões. Por conseguinte, verifica-se, ademais, que a teoria das pulsões é inacabada e que diversos comentadores afirmam que a leitura que se faz sobre a pulsão de morte é divergente; em suma, várias escolas consideram-na de formas diferentes. A multiplicidade de informações deve-se ao caráter especulativo e até mesmo mítico/poético da teoria pulsional, bem como da prudência de Freud a não querer conjecturar para além do que a prática clínica nos permite. Desse modo, o presente estudo também não deixa de ser e de acompanhar a especulação.

Todavia, de forma descritiva, é possível falar de unidade, de multiplicidade e de dualidade. Assim, fala-se de multiplicidade das pulsões quando didaticamente se busca expressar informações sobre as pulsões parciais, descritas em Três Ensaios. Fala-se em dualidade das pulsões, quando estão em contraste com a pulsão de morte - quando se considera a repetição de quantidades de energias oriundas de um não lugar além do princípio de prazer que se mesclam aos vetores posteriores ao recalque primário. A pulsão de vida, diz-nos, Freud, é visível, e a de morte só pode ser intuída em contraste com a de vida. Sobre a pulsão de morte, por si só, podemos concluir que nada podemos dizer, apenas fazer especulações. Fala-se em unidade, portanto, quando é preciso representar o impulso interno que exerce pressão constante em um organismo. 
Além disso, caracterizá-la como dual, múltipla ou unidade não deixa de abrir portas para interpretações metafísicas. Assim, dizer que ela é dual e recorrer, por exemplo, a Empédocles, implica em interpretações que levem a supor que exista algo anterior, que permita tal dualidade, ou seja, Freud recairia necessariamente numa metafísica. Contudo, é naturalista e sua herança epistemológica não aponta que Freud recorreria a princípios da psicologia espiritualista/mentalista. Segue-se também que não se trata de uma multiplicidade desde o início, pois implicaria que cada pulsão parcial já viria embutida em um bebê desde antes do nascimento, que um autista, por exemplo, já teria nascido com cada pulsão parcial isolada e vetorizada, vetorização que só ocorreria com ações específicas e traços mnêmicos iniciais. As pulsões parciais não podem ser isoladas a priori, isto é, precisa ser vetorizada pelo dialogo tônico-libidinal nas relações com a mãe, posteriormente ao nascimento.

Pode-se verificar, também, em diversos momentos, que Freud intui algo anterior à pulsão de vida, entretanto, diz-se dualista para contrapor-se a teria da libido de Jung, que avançava nos estudos sobre as neuroses narcísicas, e, pautando no idealismo alemão e no neoplatonismo, postulava que a pulsão era uma só desde o início - alma mundi - energia vital que se individuaria em muitas outras pulsões, e não só a sexual/infantil. Freud recorre a dualidade e porque a concepção celular August Weismann, postulava que parte da célula se destruía, era a única que fundamentava a hipótese de Freud. É Lacan quem observa isso e propicia mais rigor à Psicanálise, dizendo que toda pulsão é virtualmente pulsão de morte. Como virtualmente entende-se que, a rigor - teórico -, o que vem primeiro é a pulsão de morte - princípio disjuntivo do Eros, como afirma Freud. Tal exemplo é possível de ser vislumbrado no autismo, quando, segundo Lacan, há um triunfo da pulsão de morte. Afirmar que há dualidade desde o início é o mesmo que dizer que o bebê nasce com todos os traços unários já estabelecidos geneticamente, com experiências de prazer e desprazer, anteriores ao nascimento, em suma, com a pulsão de vida contida em si; ou, então, recorrer a uma explicação da psicologia espiritualista para explicar como a pulsão de vida originou-se antes do recalque primário. Ademais, no extremo oposto, identificá-la estritamente como unidade pulsional - tal como fizera Jung ao propor a alma mundi - pode levar teóricos a reconhecer uma substância, um atomismo, a priori, tal como a alma, o que, em psicanálise, é um equívoco. Disso se segue que, unidade, assim como dualidade e multiplicidade, são modos descritivos de falar da pulsão, e não podem apreender a pulsão em si mesma.

Outra dificuldade é referente à pulsão de morte, à pulsão agressiva, à pulsão de dominação e ao sadomasoquismo. A pulsão de dominação, como visto, teria origem na atividade ou passividade na manipulação das zonas erógenas; seria, portanto, uma das pulsões de vida ou noção de apoio de uma delas. Assim, não parece ser o ápice do limiar da pulsão de morte - energia tóxica se deslocando pelo psiquismo 
por não ser representada pela linguagem ou direcionada para uma atividade socialmente aceita. A pulsão agressiva, o sadomasoquismo e a pulsão de dominação parecem ser expressões da pulsão de vida e só podem ser chamadas de pulsão de morte enquanto não nomeadas pela linguagem. Fazem parte do princípio de prazer e se repetem na clínica como sintoma, inibição, angústia, formação reativa, formação substitutiva.

Contudo, acreditamos que a pulsão de morte é a primeira pulsão. É possível vislumbrar tal concepção ao se considerar o autismo, no qual, segundo Lacan, o que triunfa é a pulsão de morte. Há uma falha no recalque primário, nas primeiras inscrições resultantes da relação com o Outro, de modo que a energia permanece em estado livre e disperso, ou seja, não ligada por representações, objetos da pulsão. Houvesse uma dualidade desde o início, no autismo, não triunfaria a pulsão de morte e seria necessário recorrer a uma explicação genética ou metafísica para conjeturar sobre uma dualidade a priori. Logo, a pulsão de morte parece ser referente a algo anterior ao princípio de prazer. Todavia, como visto, a teoria pulsional freudiana permanece inacabada e tal acabamento, certamente, é proposital, visto que não buscava fazer uma cosmovisão, não buscava explicar - e quando tentava, era apenas por especulação - para além dos fatos clínicos.

\section{Referências}

ASSOUN, Paul-Laurent. Introdução à Epistemologia Freudiana. Rio de Janeiro: Imago Editora, 1983.

BEZERRA Jr. Benilton. Projeto para uma Psicologia Científica. 1.ed. Rio de Janeiro: Civilização Brasileira, 2013.

CHEMAMA, Roland. Dicionário de Psicanálise. Porto Alegre: Artes Médicas, 1995.

FREUD, Sigmund(1996a). Projeto para uma Psicologia Científica. In: Edição standard brasileira das obras psicológicas completas de Sigmund Freud. v. I. Rio de Janeiro: Imago, 1996.

FREUD, Sigmund (1996b). A Interpretação dos Sonhos. In: Edição standard brasileira das obras psicológicas completas de Sigmund Freud. v. V. I. Rio de Janeiro: Imago, 1996.

FREUD, Sigmund (1996c). Três Ensaios sobre a teoria da Sexualidade. In: Edição standard brasileira das obras psicológicas completas de Sigmund Freud. v. VII. Rio de Janeiro: Imago, 1996.

FREUD, Sigmund(1996d). Análise terminável e interminável. In: Edição standard brasileira das obras psicológicas completas de Sigmund Freud. v. XXIII. Rio de Janeiro: Imago, 1996.

FREUD, Sigmund(1996e). Além do Princípio de Prazer. In: Edição standard brasileira das obras psicológicas completas de Sigmund Freud. XVIII. Rio de Janeiro: Imago, 1996.

FREUD, Sigmund (1996f). A Negativa. In: Edição standard brasileira das obras psicológicas completas de Sigmund Freud. v. XIX. Rio de Janeiro: Imago, 1996.

FREUD, Sigmund(1996g). A questão da análise leiga. In: Edição standard brasileira das obras psicológicas completas de Sigmund Freud. v. XX. Rio de Janeiro: Imago, 1996. 
FREUD, Sigmund(1996h). O Mal-Estar na Civilização. In: Edição standard brasileira das obras psicológicas completas de Sigmund Freud. v. XXI. Rio de Janeiro: Imago, 1996.

FREUD, Sigmund(1996i). Por que a Guerra?. In: Edição standard brasileira das obras psicológicas completas de Sigmund Freud. v. XXII. I. Rio de Janeiro: Imago, 1996.

FREUD, Sigmund (2004a). Pulsões e seus destinos In: Obras Psicológicas de Sigmund Freud. v. 1. Rio de Janeiro: Imago, 2004.

FREUD, Sigmund(2004b). À Guisa de Introdução ao Narcisismo. In: Obras Psicológicas de Sigmund Freud. v. 1. Rio de Janeiro: Imago, 2004.

FREUD, Sigmund. Além do Princípio de Prazer. In: Obras Psicológicas de Sigmund Freud. v. 2. Rio de Janeiro: Imago, 2006.

FREUD, Sigmund. O Problema Econômico do Masoquismo. In: Obras Psicológicas de Sigmund Freud. v. 3. Rio de Janeiro: Imago, 2007.

FREUD, Sigmund. Epistemologia da pulsão: fantasia, ciência, mito. In: Obras incompletas de Sigmund Freud. 1.ed. Belo Horizonte: Autêntica, 2017.

FREUD, Sigmund. Neuroses de transferência: uma síntese -manuscrito recém descoberto. 1.ed. Imago, 1987.

GARCIA-ROZA, L. A. Acaso e repetição: uma introdução à teoria das pulsões. 7.ed. Rio de Janeiro: Zahar, 2003.

GOMES, A. M. A. O conceito de Energia Psíquica em Carl Gustav Jung. Disponível em: https://psicologiareligiaoeart.files.wordpress.com/2007/10/conceito-de-energia-psiquicaem-cg-jung1.pdf. Acesso: 22 Nov 2018.

LACAN, Jacques. Seminário livro 1: Os escritos técnicos de Freud. 2.ed. Rio de Janeiro: Zahar, 2009.

LACAN, Jacques. Seminário livro 1: O eu nos escritos de Freud e na técnica psicanalítica. 4.ed. Rio de Janeiro: Zahar, 1995.

LACAN, Jacques. Escritos. 2.ed. Rio de Janeiro: Zahar, 1998.

Submissão: 10.10.2018 / Aceite: 20.12.2019 